\title{
Internet resources for neurosurgeons and neuropathologists
}

\section{S Thomson, N Phillips}

\begin{abstract}
Neurosurgical and neuropathological resources on the internet are rapidly developing. Some excellent clinical, patient information, professional, academic, and teaching web sites are available. This review summarises the most useful online sites for neurosurgeons and neuropathologists in the United Kingdom and beyond. More general internet resources have been covered in the first article in this series.
\end{abstract}

See end of article for authors' affiliations

.................

Correspondence to: Mr S Thomson; SJTho@aol.com

Received 22 April 2002 In revised form 21 August 2002

Accepted 26 September 2002
O ver the past 10 years the internet has expanded rapidly. While potential benefits such as telemedicine or remote surgery have not yet been fully realised, many aspects of the internet could be more widely used. This article, in combination with the first article in this series, ${ }^{1}$ attempts to outline the current features of the internet that may be of use to practising neurosurgeons and neuropathologists in the United Kingdom and beyond.

\section{CLINICAL INFORMATION}

The Cochrane, Medline, and Best Evidence databases are popular, widely used medical resources that have been discussed earlier in this series. ${ }^{1}$ Neurosurgeons may find other less well known resources useful. Table 1 lists for easy reference some of the sites discussed below.

The Merck Manual is one of the best free online medical textbooks. The site is easy to navigate, balanced, and relatively comprehensive. The manual has been developing for over 100 years and is now in its 17th edition. It is provided by Merck, a pharmaceutical company. The neurosurgical sections provide useful, if rather simple, summaries of most neurosurgical conditions and the treatment options.

Online Mendelian Inheritance in Man presents searchable, up to date, comprehensive literature reviews and summaries. It has been developed over many years by geneticists and made available on the internet by the National Center for Biotechnology Information. It is an invaluable resource when dealing with patients with rare genetic diseases. Each entry is well structured so that even for more common diseases, relevant information can be found quickly.

Many web sites have large collections of images. Two of the best are the American Association of Neurological Surgeons (AANS) and Congress of Neurological Surgeons (CNS) site called Neurosurgery://On-call, and Neuroanatomy and Neuropathology on the Internet, which is run by the Neurology Department of the University of Debrecen, Hungary.
Neurosurgery://On-call has an "image bank" section, which has an excellent downloadable collection of radiographs. There are also some photographic images. This is a rapidly developing database, easy to search, and likely to have images relevant to most neurosurgical and neuropathological conditions.

Neuroanatomy and Neuropathology on the Internet provides a very comprehensive collection of pathological images within the online neuropathology atlas. The neuroanatomy structures subsection shows the locations of anatomical structures within normal pathological specimens. The functional neuroanatomy tables are also highly recommended. They have sections on angiogram anatomy, spinal cord lesions, and cerebral blood flow. The neurology handbook and neuroradiology links are edited and indexed lists of links to other resources on the internet. For those wanting to test their knowledge there is a quiz section. The site is kept up to date and there are links to other resources if you are unable to find what you need.

The Whole Brain Atlas has detailed magnetic resonance images and single photon emission computed tomography of the normal and pathological brain. There is a labelled brain magnetic resonance image showing detailed neuroanatomy. The site is easy to use and quick to search.

Anatomy.tv provides an astonishingly detailed collection of three dimensional anatomical models. The models may be rotated and layers slowly "dissected". The spinal model is the most relevant to neurosurgeons. Some scans and a quiz are also featured. Unfortunately, the anatomy.tv site requires an Athens subscription but most NHS trusts and universities provide this.

Neurosurgical equipment manufacturers all have web sites. These have not been listed here but there are links to most of them from the products section of the European Association of Neurosurgical Societies site. Different manufacturers' equipment can be compared. However, these web sites tend to look impressive but often provide little useful information.

Abbreviations: AANS, American Association of Neurological Surgeons; ASIT, Association of Surgeons in Training; BNTA, British Neurosurgical Trainees Association; CNS, Congress of Neurological Surgeons; CRASH, corticosteroid randomisation after significant head injury; ESPN, European Society for Pediatric Neurosurgery; ISPN, International Society for Pediatric Neurosurgery; SBNS, Society of British Neurological Surgeons; STICH, surgical trial in intracerebral haemorrhage; WFNS, World Federation of Neurosurgical Societies 
Table 1 Useful websites for neurosurgery and neuropathology

\begin{tabular}{|c|c|c|}
\hline Site name & URL & Site description \\
\hline \multicolumn{3}{|l|}{ Clinical information } \\
\hline Neuroanatomy and Neuropathology on the Internet & www.neuropat.dote.hu & - Excellent neuroanatomy and neuropathology site \\
\hline Anatomy.tv & www.anatomy.tv & - Three dimensional anatomical models \\
\hline Whole Brain Atlas & www.med.harvard.edu/AANLIB & $\begin{array}{l}\text { - Magnetic resonance images of normal and } \\
\text { pathological brains }\end{array}$ \\
\hline The Merck Manual & www.merck.com/pubs/mmanual & - Medical textbook covering neurological disease \\
\hline Online Mendelian Inheritance in Man & www.ncbi.nlm.nih.gov/Omim & - Database of rare genetic conditions \\
\hline \multicolumn{3}{|l|}{ Patient information } \\
\hline Brain and Spine Foundation (BSF) & www.bbsf.org.uk & - Patient information and list of other charity web sites \\
\hline Neurosurgery://On-call & www.neurosurgery.org & - Image bank, patient information, cyber museum \\
\hline \multicolumn{3}{|l|}{ Professional organisations } \\
\hline Society of British Neurological Surgeons (SBNS) & www.sbns.org & - Web site of the SBNS \\
\hline $\begin{array}{l}\text { European Association of Neurosurgical Societies } \\
\text { (EANS) }\end{array}$ & www.eans.org & - European examination, course, and conference \\
\hline $\begin{array}{l}\text { American Association of Neurological Surgeons } \\
\text { (AANS) }\end{array}$ & www.neurosurgery.org/aans & - Conference, Journal of Neurosurgery \\
\hline Congress of Neurological Surgeons (CNS) & www.neurosurgery.org/cns & - Conference, Neurosurgery \\
\hline World Federation of Neurosurgical Societies (WFNS) & www.wfns.org & - Worldwide neurosurgery societies and journals \\
\hline International Society for Pediatric Neurosurgery (ISPN) & www.ispn.org & $\begin{array}{l}\text { - Course, conference, and link to Child's Nervous } \\
\text { System }\end{array}$ \\
\hline European Society for Pediatric Neurosurgery (ESPN) & www.espneurosurgery.org & - Course and conference details \\
\hline British Neuropathological Society & www.bns.org.uk & - Conference, mailing list, and news \\
\hline Royal College of Surgeons of Edinburgh & www.rcsed.ac.uk & \\
\hline Royal College of Surgeons in Ireland & www.rcsi.ie & \\
\hline Royal College of Surgeons of England & www.rcseng.ac.uk & \\
\hline Royal College Physicians and Surgeons of Glasgow & www.rcpsglasg.ac.uk & \\
\hline Royal College of Pathologists & www.rcpath.org & \\
\hline Doctor to Doctor & www. doctortodoctor.org & - Neurosurgical mailing list \\
\hline \multicolumn{3}{|l|}{ Academic resources } \\
\hline British Neurosurgical Trainees Association (BNTA) & www.bnta.org & $\begin{array}{l}\text { - Courses, conferences, mailing list, logbooks, and } \\
\text { training }\end{array}$ \\
\hline $\begin{array}{l}\text { Joint Committee on Higher Surgical Training (JCHST) } \\
\text { (and Specialist Advisory Committees) }\end{array}$ & www.jchst.org & - Training regulations \\
\hline Intercollegiate Specialty Boards & www.intercollegiate.org.uk & - Examination dates, locations, and syllabus \\
\hline British Neurosurgical Research Group (BNRG) & www.ncl.ac.uk/bnrg & - Conference details \\
\hline Cervical Spine Research Society & www.csrs.org & - Conference details \\
\hline $\begin{array}{l}\text { Corticosteroid randomisation after significant head } \\
\text { injury trial }\end{array}$ & www.crash.Ishtm.ac.uk & - Protocol, recruitment progress \\
\hline Surgical trial in intracerebral haemorrhage & www.ncl.ac.uk/stich & - Protocol, recruitment progress \\
\hline \multicolumn{3}{|l|}{ Teaching resources } \\
\hline $\begin{array}{l}\text { Web-Based Surgical Simulators and Medical } \\
\text { Education Tools }\end{array}$ & $\begin{array}{l}\text { synaptic.mvc.mcc.ac.uk/ } \\
\text { simulators.html }\end{array}$ & - Lumbar puncture and external ventricular drain tutor \\
\hline Interactive Atlases: Digital Anatomist Project & vertex.biostr.washington.edu/da.html & - Anatomical diagrams and quizzes \\
\hline
\end{tabular}

Uniform resource locators (URLs) correct on 30 September 2002. These URLs are downloadable as a Bookmarks/Favorites file from the JNNP web site (www.jnnp.com).

\section{PATIENT INFORMATION}

More and more homes in the developed world have access to the internet and this trend is likely to continue. Fourteen million people (of about 60 million inhabitants) use the internet regularly in the United Kingdom. Searching for health related information is one of the commonest reasons to go on line. ${ }^{2}$ Patients wish to be better informed and clinicians are spending an increasing amount of time directing patients towards good health care information sites.

The best general patient information sites are NHS Direct (www.nhsdirect.nhs.uk) and its American equivalent, healthfinder (www.healthfinder.gov). Frequently these sites provide too little information on rare conditions. They are, however, well designed, easy to navigate, and kept up to date.

Reliable neurosurgical information for patients can be found on the Brain and Spine Foundation site. The Brain and Spine Foundation produce a wide range of leaflets that can be downloaded free of charge or purchased directly. The Foundation also maintains a list of charity web sites with more specific patient information. These include BackCare (www. backpain.org), Headway (www.headway.org.uk), the British Acoustic Neuroma Association (www.ukan.co.uk/bana), CancerBACUP (www.cancerbacup.org.uk), and The Pituitary
Foundation (www.pituitary.org.uk). All of these excellent sites have their own information and support networks. Neurosurgery://On-call provides a patient's guide to neurosurgery and is a North American view of neurosurgical practice. The Driver and Vehicle Licensing Agency (www.dvla.gov.uk) is a good resource for patients wishing to retain their driving licence after neurosurgical procedures.

Some neurosurgical centres in the United Kingdom have departmental web sites, including Dundee (www.dundee. ac.uk/neurosurgery), Liverpool (www.thewaltoncentre.co.uk), Birmingham (medweb.bham.ac.uk/neurosurgery), and Bristol (www.neurosurgery.uk.net). Of these the Liverpool site is the most informative, giving detailed information to local patients. While it is not possible to look up surgical performance figures these may soon become available to the public over the internet.

\section{PROFESSIONAL ORGANISATIONS}

The royal colleges of surgeons in Edinburgh, Dublin, London, and Glasgow, as well as the Royal College of Pathologists, all have excellent web sites. Information on courses, conferences, examinations, political activities, and college facilities are 
Table 2 A selection of popular neurosurgical online journals

\begin{tabular}{|c|c|c|c|}
\hline Journal name & URL & Free abstracts & Email table of contents \\
\hline Journal of Neurosurgery & www.thejns-net.org & Some & Subscribers only \\
\hline Neurosurgery & www.neurosurgery-online.com & Yes & Yes \\
\hline Journal of Neurology, Neurosurgery \& Psychiatry* & www.jnnp.com & Yes & Yes \\
\hline Spine & www.spinejournal.com & Yes & Yes \\
\hline Acta Neurochirurgica & www.link.springer.de/link/service/journals/00701 & Yes & Yes \\
\hline Surgical Neurology & www.medicinedirect.com/journal/journal?sdid=5166 & Yes & Yes \\
\hline Neurosurgery Clinics of North America & $\begin{array}{l}\text { www2. us.elsevierhealth.com/scripts/om.dll/serve?act } \\
\text { ion=searchDB\&searchDBfor=home\&id=cnsu }\end{array}$ & No & No \\
\hline Child's Nervous System & www.link.springer.de/link/service/journals/00381 & Yes & Yes \\
\hline Neurosurgery Quaterly & www.neurosurgery-quarterly.com & Yes & No \\
\hline Minimally Invasive Neurosurgery & www.thieme.de/min & Yes & Yes \\
\hline Pediatric Neurosurgery & www.karger.com/journals/pne/pne_jh.htm & Yes & Yes \\
\hline British Journal of Neurosurgery* & www.tandf.co.uk/journals/titles/02688697.html & Yes & Yes \\
\hline
\end{tabular}

*Journals that offer electronic paper tracking. URLs correct on 30 September 2002. These URLs are downloadable as a Bookmarks/Favorites file from the

* Journals that offer electronic paper
JNNP web site (www

JNNP web site (www.jnnp.com).

available. These sites are all well designed, professionally maintained, and up to date.

At the time of writing, the Society of British Neurological Surgeons (SBNS)is still developing its web site, but the European Association of Neurosurgical Societies (EANS) (www. eans.org) has an excellent and recently updated site with details of forthcoming meetings, courses, and the European neurosurgical examination. There are links to all the European neurosurgical societies and to the journal Acta Neurochirgica. There are some useful links particularly to product manufacturers. The information section details some useful internet resources. The site is well designed, effectively presented, easy to navigate, and informative.

The International Society for Pediatric Neurosurgery (ISPN) has a regularly updated site carrying details of the ISPN conference, course, and news. Electronic abstract submission is available and there is a link to the journal Child's Nervous System. The site is easy to use and intuitive. The European Society for Pediatric Neurosurgery (ESPN) has its own web site with details of the ESPN course and conference.

The joint AANS and CNS web site Neurosurgery://On-call links to the subsidiary CNS and AANS web sites. Neurosurgery://On-call is a leading neurosurgical resource on the world wide web. There is a large searchable image bank with sample images of most neurosurgical conditions. There are links to the journals Neurosurgery and Journal of Neurosurgery. Neurosurgical Focus is an online journal run from this site with free full text articles. The site also allows registration, program assessment, and abstract submission for the AANS and CNS meetings. The patient information is balanced, cautious, and not inappropriate for British neurosurgical patients to read. The cyber museum outlines the history of neurosurgery in an original, easy to navigate format. The home page may appear a bit overcrowded, making the useful parts of this site more difficult to find.

The World Federation of Neurosurgical Societies (WFNS) web site has comprehensive lists of worldwide neurosurgical societies and journals. It carries information on the WFNS conferences, courses, and scholarships, as well as some book reviews.

The British Neuropathological Society maintains an excellent web site with details of courses and conferences, and a mailing list. The site is detailed, well presented, and easy to navigate.

Mailing lists offer an excellent way to maintain contact with neurosurgeons or neuropathologists beyond a single department. Clinical cases can be discussed and an idea of how problems are managed elsewhere can be obtained. There are a number of mailing lists, such as these examples:
- Doctor to Doctor, which is a useful, free neurosurgical discussion forum divided into subspecialty areas. Cases are usually well illustrated and educational. Difficult cases can be discussed with a worldwide group of neurosurgeons. The doctor to doctor discussion forum is run by Neurosurgery International (www.nsinternational.org), a group dedicated to providing neurosurgical support to developing countries.

- The British Neurosurgical Trainees Association (BNTA) mailing list has over 100 participants with members in every neurosurgical centre in the United Kingdom. Membership is restricted to neurosurgical registrars working in the United Kingdom.

- The British Neuropathological Society has a mailing list for its members

\section{ACADEMIC RESOURCES}

Many independent conference organisers are establishing their own web sites, which include program details, electronic abstract submission, and registration. Last minute announcements may also be made on the conference web site. Neurosurgical conferences with permanent web sites include The British Neurosurgical Research Group, The Royal Society of Medicine Clinical Neurosciences Section (www.rsm.ac.uk/ academ/smtcn.htm), and the Cervical Spine Research Society. The WFNS, EANS, AANS, CNS, and ISPN conferences may be accessed from their respective society web sites. The SBNS conference will be featured on the newly developed SBNS site.

Many neurosurgical journals are available on line. Neurosurgery Focus (www.neurosurgery.org/focus), Reviews in Neurosurgery (www.wfns.org/reviews_neuro.html), and Annals of Neurosurgery (www.annals-neurosurgery.org) offer free, full text articles with rapid publication. Copyright usually remains with the authors. All other journals have web sites with instructions for authors, abstracts, current tables of contents, and online subscription. Full text is available through institutional or individual subscriptions. Table 2 summarises the web sites of the neurosurgical journals with the highest impact factors. The WFNS site has a list of over 150 other neurosurgical journals.

Consultants and trainees will find the BNTA web site a useful resource, as it carries details of courses, conferences, examinations, and the current training system in the United Kingdom. It has downloadable logbooks and links to the BNTA mailing list, pathology, anatomy, and journal sites. The Association of Surgeons in Training (ASIT) also has a web site (www.asit.org) and mailing list, from which details of the ASIT conference can be obtained. 
The STICH (surgical trial in intracerebral haemorrhage) and the CRASH (corticosteroid randomisation after significant head injury) trial have informative web sites on entering patients into the trials and on progress so far.

\section{TEACHING RESOURCES}

There are online simulators for learning the techniques of lumbar puncture, radiofrequency lesioning of the trigeminal nerve, transpedicular screw fixation, and insertion of an external ventricular drain. The external ventricular drain simulator has recently been updated. The Manchester Visualisation Centre, Leeds Department of Neurosurgery, and Leeds School of Computing have developed these simulators.

The Digital Anatomist Project is a good online anatomy teaching resource. It has been produced by the University of Washington in Seattle. The neuroanatomy interactive syllabus is organised into functional chapters and provides excellent anatomical diagrams and quizzes.

Courses are increasingly advertised on the internet. All four web sites of the royal colleges of surgeons carry course details. Independent courses frequently have their own web sites. The BNTA web site carries an up to date list of courses.

Details of the FRCS ( SN) examination can be obtained from the Intercollegiate Specialty Boards web site. This is the quickest and easiest way to check examination times, locations, and syllabus content. The EANS site carries details of the European neurosurgical examination. The Joint
Committee on Higher Surgical Training and Specialist Advisory Committees share a web site. Training details, rules, and regulations can be accessed.

\section{CONCLUSIONS}

This article is a brief overview of some of the most useful web sites; many more will rapidly develop. The internet based revolution in medical informatics is going to change the way that neurosurgery and neuropathology are practised. Patients will be much better informed about their conditions and the available treatments. If, as clinicians, we do not want to be left behind by our own patients, then we must learn to accept this new technology and use it to its full potential.

\section{Authors' affiliations}

S Thomson, N Phillips, Department of Neurosurgery, Leeds General Infirmary, 1 Great George Street, Leeds LS 1 3EX, UK

Conflicts of interests: None

\section{REFERENCES}

1 Al-Shahi R, Sadler M, Rees G, et al. The internet. J Neurol Neursurg Psychiatry 2002;73:611

2 Powell J. The WWW of the World Wide Web: who, what, and why? J Med Internet Res 2002;4:e4 